\title{
Manifestasi dan Komplikasi Gastrointestinal pada Purpura Henoch Schonlein
}

\author{
Martani Widjajanti \\ SMF Anak, RSAB Harapan Kita, Jakarta
}

Latar belakang. Purpura Henoch Schonlein (PHS) merupakan penyakit vaskulitis sistemik yang sering terjadi pada anak. Gejala yang timbul pada PHS seringkali melibatkan berbagai organ, mulai dari kulit, persendian, saluran cerna, ginjal, dan organ lain. Permasalahan pada sistem gastrointestinal termasuk yang sering dijumpai pada pasien PHS dengan gejala bervariasi dari ringan sampai berat.

Tujuan. Mengetahui manifestasi klinis PHS dan komplikasi yang mengenai sistem gastrointestinal di RSAB Harapan Kita Jakarta.

Metode. Penelitian deskriptif data dari Rekam Medik pasien PHS di RSAB Harapan Kita Jakarta dalam kurun waktu 7 tahun, yaitu sejak Januari 2004 sampai dengan Desember 2010. Subyek penelitian mencakup semua pasien anak usia di bawah 18 tahun yang didiagnosis PHS. Dilakukan pencatatan dan penilaian manifestasi klinis dan komplikasi yang terjadi pada sistem gastrointestinal.

Hasil. Didapat 70 kasus PHS, dengan rentang usia antara 2 tahun sampai dengan 16 tahun. Pasien lakilaki 39 (55,7\%) lebih banyak daripada perempuan 31 (44,3\%) anak. Semua pasien mengalami purpura, dan kelainan gastrointestinal dijumpai pada 50 (71,4\%) kasus, gangguan persendian pada $30(42,9 \%)$ kasus sedangkan kelainan pada ginjal dijumpai pada $11(15,8 \%)$ kasus. Manifestasi klinis pada sistem gastrointestinal berupa nyeri perut 41 (82\%) kasus, muntah 28 (56\%) kasus, konstipasi 11 (22\%) kasus, dan melena 6 (12\%) kasus. Komplikasi pada sistem gastrointestinal adalah perdarahan masif 1(2\%) kasus dan intususepsi ringan $1(2 \%)$ kasus.

Kesimpulan. Manifestasi klinis sistem gastrointestinal pada PHS sering dijumpai. Manifestasi klinis tersering yang dikeluhkan berupa nyeri perut, terkadang mendahului terjadinya purpura pada kulit, sehingga menyulitkan diagnosis. Komplikasi yang ditemukan adalah perdarahan masif dan intususepsi, namun tidak memerlukan tindakan pembedahan. Sari Pediatri 2012;13(5):334-9.

Kata kunci: purpura Henoch Schonlein, anak, manifestasi, gastrointestinal

\footnotetext{
Alamat korespondensi:

Dr. Martani Widjajanti, Sp.A. RS Anak dan Bunda Harapan Kita Jakarta, Jl. Letjen S. Parman Kav. 87, Slipi, Jakarta.
}

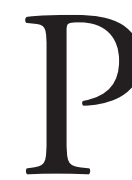

urpura Henoch Schonlein (PHS), merupakan penyakit sistemik, berupa vaskulitis pada pembuluh darah kecil yang dapat mengenai kulit, persendian, sistem gastrointestinal, dan ginjal. ${ }^{1,2}$ Penyakit PHS pertama kali ditemukan oleh Lucas Schonlein pada tahun 1832 dan Eduard Henoch 
pada tahun $1874 .{ }^{3}$ Penyebab PHS masih belum jelas, namun dapat terjadi sesudah infeksi saluran napas atas, reaksi hipersensitivitas, atau pemberian obatobatan. ${ }^{3,4}$

Angka kejadian pertahun berkisar antara 13.518/100 000 anak, 50\% kasus terjadi pada anak-anak di bawah usia 5 tahun dan 75\% kasus terjadi pada usia di bawah 10 tahun. Pasien PHS lebih banyak dijumpai pada anak laki-laki. ${ }^{2,4}$ Kriteria diagnosis PHS menurut European League Against Rheumatism/EULAR (2006) $)^{1,5}$ apabila ditemukan purpura (umumnya teraba) atau petekiae dengan lokasi predominan di tungkai bawah ditambah satu dari empat kriteria berikut, nyeri perut, artritis atau artralgia, histopatologi menunjukkan vaskulitis leukositoklastik dengan predominan deposit IgA atau proliferasi glomerulonefritis dengan predominan deposit Ig A, serta adanya keterlibatan ginjal (proteinuria dan atau hematuria).

Menurut Chen dan Kong, ${ }^{3}$ 50\%-80\% dari total pasien PHS mengalami kelainan gastrointestinal dengan manifestasi mual, muntah, diare, nyeri kolik, dan perdarahan saluran cerna. Nyeri perut yang ditemukan selalu bersifat kolik dan sulit dilokalisir. ${ }^{6}$ Pemeriksaan fisis pada abdomen dapat ditemui adanya distensi dan kadang menampilkan keadaan yang menyerupai gejala abdomen akut sehingga mengakibatkan laparotomi eksplorasi yang tidak perlu. ${ }^{6}$

Gejala gastrointestinal disebabkan adanya ekstravasasi darah dan cairan ke dinding usus yang mengakibatkan ulserasi mukosa usus dan terkadang perdarahan. ${ }^{8,11}$ Komplikasi pada saluran cerna dapat berupa perdarahan masif, perforasi usus atau nekrosis dan intususepsi. Pada beberapa tahun terakhir, para peneliti melaporkan kasus dengan manifestasi baru pada sistem gastrointestinal, yaitu berupa hemorrhagic ascites, perforasi usus besar dan kecil, pancreatitis, dan iskemi dari duktus bilier. ${ }^{7}$

Deteksi dini kelainan gastrointestinal pada PHS sangat penting karena kadang-kadang membutuhkan intervensi bedah. ${ }^{3}$ Pemeriksaan pencitraan yang dilakukan seperti foto abdomen, ultrasonografi, dan $C T$ scan dapat digunakan untuk membantu membedakan pasien yang perlu intervensi bedah atau tidak, sedangkan data laboratorium tidak dapat digunakan untuk tujuan tersebut. ${ }^{3,5}$ Tujuan penelitian untuk mengetahui manifestasi klinis dan komplikasi pada sistem gastrointestinal yang terjadi pada pasien PHS yang berobat di RSAB Harapan Kita, Jakarta.

\section{Metode}

Penelitian deskriptif analitik dilakukan, berdasarkan data retrospektif dari rekam medis pasien anak yang dirawat di Instalasi Rawat Inap dan Instalasi Rawat Jalan anak di RSAB Harapan Kita dalam kurun waktu Januari 2004 sampai dengan Desember 2010. Subyek penelitian adalah semua pasien yang berusia di bawah 18 tahun dengan diagnosis PHS, memiliki data rekam medis lengkap, mencakup identitas, anamnesis, pemeriksaan fisik, dan pemeriksaan penunjang sesuai indikasi. Pemeriksaan penunjang adalah darah tepi dan urinalisis, ultrasonografi abdomen, foto abdomen, atau endoskopi. Penelitian ditujukan terutama pada manifestasi gastrointestinal, yaitu nyeri perut, muntah, diare, dan/atau perdarahan saluran cerna bawah berupa melena, dan komplikasi gastrointestinal berupa perdarahan masif, intususepsi, dan perforasi. Data yang diperoleh dimasukkan dalam program komputer SPSS 17.00 dan dianalisis secara deskriptif dengan tampilan frekuensi dan presentase.

\section{Hasil}

Dalam kurun waktu Januari 2004 hingga Desember 2010, di RSAB Harapan Kita didapatkan 70 pasien PHS yang terdiri dari 23 pasien rawat jalan dan 47 pasien rawat inap yang memenuhi kriteria studi penelitian. Sebaran subjek berdasarkan jenis kelamin adalah 39 orang laki-laki $(55,7 \%)$ dan 31 orang perempuan $(44,3 \%)$, berusia 2 tahun sampai dengan 16 tahun, dengan rerata terbanyak pada usia 9 tahun (9 kasus). Distribusi jumlah kasus tertera pada Gambar 1.

Semua pasien mengalami purpura, kelainan gastrointestinal dijumpai pada $50(71,4 \%)$ kasus, gangguan persendian pada $30(42,9 \%)$ kasus, dan kelainan ginjal $11(15,8 \%)$ kasus. Keluhan yang membuat pasien datang berobat cukup bervariasi, terbanyak mengeluh kemerahan di kulit $46(65,8 \%)$ kasus, diikuti dengan nyeri perut $12(17,1 \%)$ kasus, keluhan sendi 7 (10\%) kasus, mual dan muntah 4 $(5,7 \%)$ kasus, serta melena $1(1,4 \%)$ kasus. Pada pemeriksaan fisis dan pemantauan selanjutnya, 50 kasus menunjukkan gambaran manifestasi gastrointestinal yang berupa nyeri perut $12(24 \%)$, nyeri perut dan muntah $12(24 \%)$, nyeri perut dan konstipasi $5(10 \%)$, muntah 3 (6\%), konstipasi 1 (2\%), muntah dan diare 
2 (4\%), muntah dan konstipasi 2 (4\%), muntah, nyeri perut dan konstipasi $3(6 \%)$, muntah, nyeri perut dan diare $2(4 \%)$, muntah, melena dan nyeri perut $4(8 \%)$, nyeri perut dan diare $2(4 \%)$, nyeri perut dan melena 1 (2\%), dan melena 1 (2\%) kasus (Gambar 2).
Manifestasi gastrointestinal pada pasien PHS, dari 50 kasus didapatkan nyeri perut total 41 (82\%), muntah 28 (56\%), konstipasi 11 (22\%), dan melena $6(12 \%)$ kasus. Tidak semua pasien dilakukan pemeriksaan penunjang. Di antara 70 kasus PHS

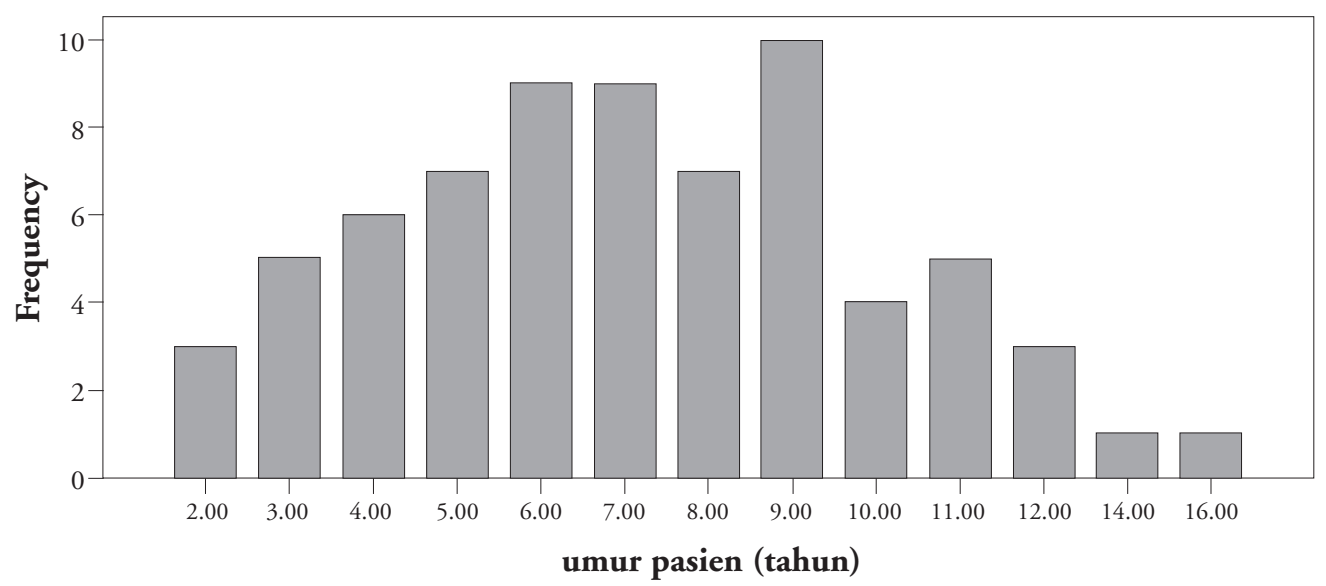

Gambar 1. Distribusi jumlah pasien HSP berdasarkan usia, tahun 2004-2010

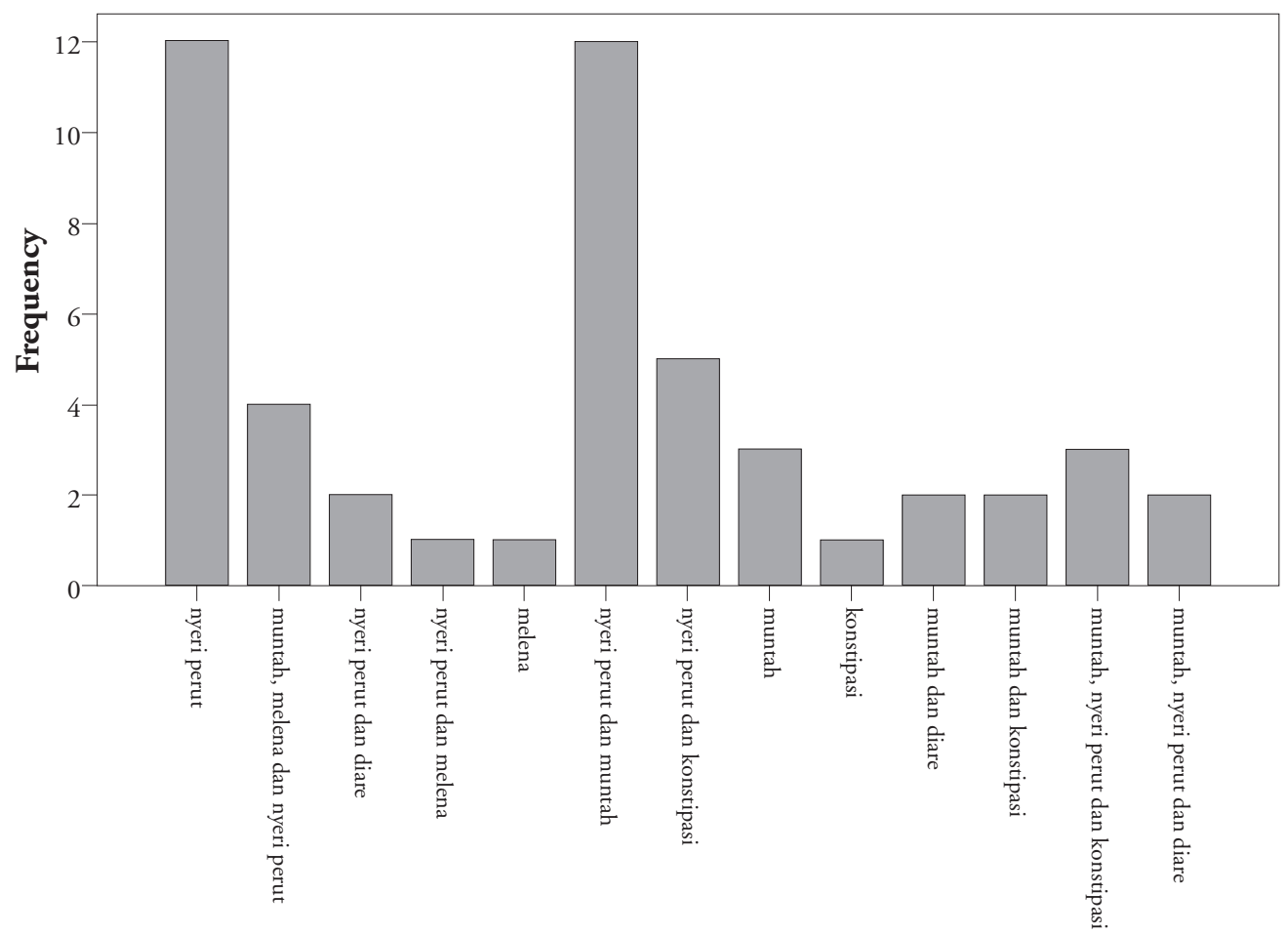

Gambar 2. Manifestasi gastrointestinal pada PHS 


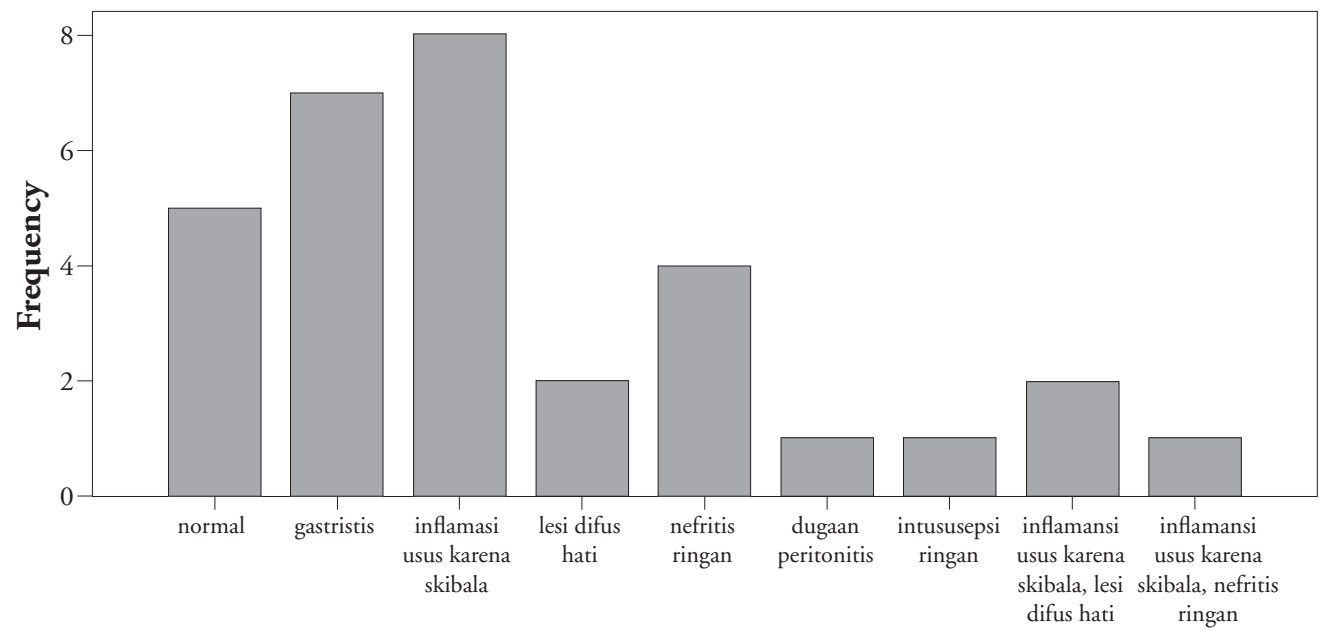

Gambaran USG

Gambar 3. Gambaran Ultrasonografi abdomen pada PHS

yang diteliti, 59 kasus menunjukkan, kadar $\mathrm{Hb}$ $<10 \mathrm{~g} / \mathrm{dL}$ pada $6(8,8 \%)$, kadar leukosit $>10.000 /$ uL pada $33(47,1 \%)$, sedangkan peningkatan kadar trombosit $>400.000 / \mathrm{uL}$ dijumpai pada $18(25,7 \%)$ kasus. Pemeriksaan urinalisis yang dilakukan pada 50 kasus, dijumpai hematuria $5(10 \%)$, proteinuria 1 $(2 \%)$, sedangkan hematuria yang dijumpai bersamaan dengan proteinuria terdapat pada 5 (10\%) kasus. Pada 20 kasus, 4 kasus di antaranya ditemukan eritrosit di dalam pemeriksaan tinja. Pemeriksaan penunjang lain yang dilakukan adalah foto abdomen, ultrasonografi abdomen, atau endoskopi. Pemeriksaan foto abdomen dilakukan pada 4 kasus, dengan hasil tidak tampak tanda perforasi maupun obstruksi usus.

Ultrasonografi abdomen dilakukan pada 31 kasus, normal pada $5(16,1 \%)$, gambaran gastritis pada $7(22,6 \%)$, inflamasi usus karena skibala 11 $(35,5 \%)$, lesi difus pada hati $4(13 \%)$, nefritis ringan 5 $(16,1 \%)$, dugaan peritonitis $1(3,2 \%)$ dan intususepsi ringan $1(3,2 \%)$ kasus. Terdapat satu kasus dengan manifestasi muntah dan melena yang cukup hebat, sehingga dianggap perlu untuk dilakukan pemeriksaan gastroskopi. Pada pemeriksaan gastroskopi dijumpai ulkus duodenum dan gastritis erosif, pada biopsi ditemukan duodenitis derajat 2 dan gastritis kronik non atrofi.

Di antara 70 kasus pasien PHS, didapatkan 5 $(1,4 \%)$ kasus rujukan dari rumah sakit lain, dengan diagnosis awal apendisitis dan kemudian dilakukan apendektomi. Pada pengamatan selanjutnya, karena dijumpai ruam kulit, pasien dirujuk ke RSAB HK, dan ditegakkan diagnosis PHS. Dari catatan medik didapatkan bahwa nyeri perut timbul sekitar 2-3 hari sebelum timbul ruam, interval waktu dari gejala nyeri perut sampai dilakukan apendektomi bervariasi antara 2-7 hari, sedangkan interval waktu dari apendektomi hingga dibuat diagnosis PHS berkisar 6-7 hari.

\section{Pembahasan}

Purpura Henoch Schonlein merupakan penyakit sistemik vaskulitis tersering pada anak yang ditandai dengan purpura yang teraba, tanpa trombositopenia, nyeri perut, arthritis, dan gangguan ginjal..$^{8,13}$ Menurut Ramakrishnan, ${ }^{2}$ PHS terjadi $50 \%$ pada usia $<5$ tahun dan $75 \%$ pada usia $<10$ tahun. Pada penelitian kami dijumpai 30\% kasus berusia kurang dari 5 tahun dan $55,7 \%$ pada usia kurang dari 10 tahun, dengan rerata pada usia 9 tahun. Beberapa penulis menyatakan bahwa PHS lebih sering dijumpai pada laki-laki daripada wanita dengan perbandingan 1,8:1. ${ }^{9}$ Kami mendapatkan pasien laki-laki sedikit lebih banyak dibandingkan pasien perempuan, dengan perbandingan $1,25: 1$.

Manifestasi PHS dapat melibatkan berbagai organ mulai dari kulit, sistem gastrointestinal, sendi, dan ginjal, ${ }^{1,2,10}$ yaitu berturut-turut $71,4 \%, 42,9 \%$, dan $15,9 \%$ kasus. 
Penelitian yang dilakukan oleh Kumar $\mathrm{dkk}^{10}$ menyatakan bahwa nyeri perut terjadi pada lebih dari setengah jumlah kasus, dan manifestasi tersering berupa kolik abdomen. Nyeri pada umumnya berhubungan dengan mual, muntah, diare atau konstipasi serta di jumpai darah atau lendir pada tinja. ${ }^{4}$ Menurut Chen dan Kong, ${ }^{3} 50 \%-80 \%$ dari total pasien PHS yang diteliti, menunjukkan kelainan gastrointestinal dengan manifestasi mual, muntah, diare, nyeri kolik, dan perdarahan traktus gastrointestinal. Kami lebih banyak menemukan nyeri perut, nyeri perut dan muntah, dan nyeri perut disertai konstipasi. Diare, buang air besar hitam dan buang air besar berdarah jarang dijumpai.

Lima kasus rujukan dari rumah sakit lain telah menjalani operasi apendektomi sebelum diagnosis PHS ditegakkan. Hal tersebut mungkin disebabkan gejala nyeri perut yang timbul dan pemeriksaan fisis yang dilakukan sangat mirip dengan gejala apendisitis akut yang memerlukan tindakan operasi segera. Setelah dijumpai gejala ruam merah di kulit yang makin nyata, diagnosis PHS baru mulai dipikirkan. Pada kasus tersebut, gejala gastrointestinal timbul lebih dahulu atau bersamaan dengan kemerahan pada kulit, sehingga diagnosis PHS terlambat ditegakkan. Hal tersebut sesuai dengan penelitian Lanzkowsky ${ }^{11}$ yang menyatakan bahwa diagnosis PHS kadang dapat sulit ditegakkan, terutama ketika gejala abdominal timbul lebih dahulu daripada purpura. Menurut Lawee, ${ }^{12}$ gejala abdomen yang timbul mulai dari mual, muntah dan distensi abdomen memang sering membingungkan para dokter, apalagi apabila disertai dengan gejala akut abdomen yang mengakibatkan tindakan laparotomi yang tidak diperlukan.

Chen $\mathrm{dkk}^{6}$ menyatakan bahwa pada pasien PHS nyeri perut yang ditemukan bersifat kolik dan sulit dilokalisasi. Dari pemeriksaan fisik abdomen, ditemui distensi, dan kadang-kadang menampilkan keadaan yang menyerupai akut abdomen sehingga mengakibatkan laparotomi eksplorasi yang tidak perlu. Komplikasi sistem gastrointestinal tersering pada pasien PHS menurut beberapa peneliti yaitu intususepsi, perforasi, dan perdarahan masif. ${ }^{4,5,12}$ Gejala gastrointestinal merupakan akibat dari ekstravasasi darah dan cairan ke dinding usus yang mengakibatkan ulserasi mukosa usus dan terkadang perdarahan. ${ }^{13}$ Kami temukan satu orang yang dilakukan gastroskopi karena menunjukkan gejala muntah dan melena hebat. Dari hasil gastroskopi dijumpai ulkus duodenum dan gastritis erosif, hasil biopsi menunjukkan duodenitis derajat II dan gastritis kronis non atrofi. Selain itu, dijumpai satu kasus lainnya dengan intususepsi ringan berdasarkan hasil ultrasonografi abdomen, namun pada pemantauan selanjutnya ternyata tidak diperlukan tindakan bedah, pasien dapat dinyatakan sembuh dan pulang dalam kondisi baik.

Deteksi dini manifestasi dan komplikasi gastrointestinal pada pasien PHS sangat penting, karena tata laksana yang kurang tepat dan cepat dapat memperburuk prognosis. Kadang-kadang dibutuhkan pemeriksaan penunjang/pencitraan seperti foto abdomen, ultrasonografi abdomen, atau CT scan abdomen untuk membedakan pasien yang perlu intervensi bedah atau tidak. ${ }^{3,5}$

\section{Kesimpulan}

Purpura Henoch Schonlein merupakan penyakit sistemik vaskulitis tersering pada anak dengan angka kejadian paling sering di bawah usia 10 tahun, ditemukan lebih banyak pada laki-laki dibanding perempuan. Manifestasi PHS beraneka ragam mulai dari purpura, nyeri perut, nyeri sendi dan gangguan ginjal. Manifestasi pada sistem gastrointestinal yang sering dijumpai yaitu nyeri perut, muntah, diare atau konstipasi. Gejala gastrointestinal timbul mendahului gejala ruam pada kulit sehingga menyulitkan diagnosis. Komplikasi pada gastrointestinal berupa perdarahan masif dan intususepsi ringan, tidak memerlukan tindakan pembedahan.

\section{Daftar pustaka}

1. Brogan P, Eleftheriou D, Dillon M. Small vessel vasculitis. Pediatr Nephrol 2010; 25:1025-35.

2. Ramakrishnan L, Vamvakiti E, Remorino R. Clinical problem : HSP- Henoch Schonlein Purpura. Chichester: St. Richard's Hospital, 2008.

3. Chen SY, Kong MS. Gastrointestinal manifestations and complications of HSP. Chang Gung Med J 2004;27:175-80.

4. Robert PF, Waller TA, Brinker TM, Riffe IZ, Sayre JW, Bratton RL. Henoch Schonlein Purpura : a review article. Southern Med J 2007;100:820-4.

5. Karasmanis RH, Ronald GS, Maria R, Donald AS. Abdominal wall and labial edema presenting in a girl with HSP : a case report. J Med Case Reports 2010;98:1-4. 
6. Chen MJ, Wang TE, Chang WH, Tsai SJ, Liao WS. Endoscopic findings in a patient with Henoch Schonlein Purpura. World J Gastroenterol 2005;11:2354-2356.

7. Rai A, Nast C, Adler S. HSP Nephritis. J Am Soc Nephrol 1999;10:2637-44.

8. Ballinger S. Henoch-Schonlein Purpura. Curr Opinion Rheumatol 2003; 15:591-4.

9. Lim DCE, Cheng LNC, Wong FWS. Could it be Henoch Schonlein Purpura. Aust Fam Physician 2009;38:321-4.
10. Kumar L, Signh S, Gorava JS. Henoch Schonlein Purpura : the Chandigarh experience. Indian Ped 1998;35:19-25.

11. Lanzkowsky S, Lanzkowsky L, Lanzkowsky P. HenochSchoenlein purpura. Pediatr Rev 1992;13:130-7.

12. Lawee D. Atypical clinical course of Henoch Schonlein Purpura. Can Fam Physician 2008;54:1117-20.

13. Sohagia AB, Gunthuru SG, Tong TR, Hertan HI. Henoch Schonlein Purpura. Hindawi Publishing Corporation . New York: Gatroenterology Research and Practice; 2010. 